\title{
16. Improving road safety: perspectives from Victoria's Transport Accident Commission
}

\author{
Janet Dore
}

Victoria became the first jurisdiction in the world to introduce compulsory seatbelts in 1970. Since then the state has become a pioneer in making progress on road trauma and reducing the death rate on the state's roads. This chapter will outline the challenges involved in getting to this stage, the progress made, and the reforms that are still to be achieved.

\section{The role of the Transport Accident Commission}

In the 1960s the road toll in Victoria was more than 1000 deaths per year, and by the 1970s it was still more than 800 deaths. To address this, the Transport Accident Commission (TAC) was established in 1986 and launched a series of hard-hitting advertising campaigns, which saw the death toll begin to decline. We have become well known for these campaigns, including the iconic television advertisements with 'Katie' in the rehabilitation unit, and the slogans 'Drink, drive, bloody idiot' and 'Don't fool yourself, speed kills'.

But no matter how notorious these campaigns have become, the TAC realised that further policy reform was required to save more lives. Working with our road-safety partners at Victoria Police, the Department of Justice and Vic Roads, we created a state government policy strategy called 'Arrive Alive'. This is a 10year government strategy in conjunction with our road-safety partners based on evidence that shows improving road safety boils down to three main factors: safer cars, safer roads and safer road users.

Let me put it another way: if everyone was a five-star driver, in a five-star car, on a five-star road, the TAC would not need to exist because the levels of accidents and injury would fall dramatically, if not be eliminated. Further, the technology in new cars these days will make it possible that in another generation's time the cars themselves could be too intelligent to have accidents.

Why then did we at the TAC initially focus on the 'safer car' issue part of this system, and apply that to the lessons of policy reform and making them stick? The safer car part of the equation was always the one with a lag, so that is why we decided to focus on it. We know we can treat intersections, build safer roads, and can achieve much through the police with trying to get better road users, but the TAC has always tried to be bold and creative in its approach to road safety. 
To date, the Victorian fleet has some emphasis on environmental issues, but perhaps not so much commitment to the five-star safety rating, and that should concern us as a community. That finding should make all of us stop and think about which car we are currently driving. So, from a public-policy perspective, how do we get Victorians into safer cars? It was more than a decade ago now that the evidence started to emerge that vehicle safety features could have a powerful impact on road-safety figures. And the Monash University Accident Research Centre (MUARC) found that if we all could drive the safest car in our class, road trauma levels would drop by one-third. In practical terms, that would result in saving about 100 lives per year, and reducing injuries by their thousands, because we have 46 serious injuries on our roads every single day in addition to the number of road fatalities. So road trauma includes the figures behind the road toll, and if we could reduce the magnitude of road accidents it would save thousands of people every year the impact of road trauma.

Before I highlight a particular case study from our experience, I must first explain that the Victorian TAC is unique in Australia. We are a no-fault insurer on behalf of the government, whereas other states have fault-based insurance systems that are either government owned, or operate within a competitive market, as in New South Wales and Queensland. I believe our reputation will eventually lead other governments to adopt the Victorian model. We are pushing the Victorian model and its success in the discussions on the National Disability Insurance Scheme, to show that this kind of no-fault scheme can work effectively provided we get a good source of revenue. There is some access to common law in Victoria, and that is always the pressure point. In other states they have full access to common law and that is where things start unravelling.

\section{Reforming road safety: lessons from experience}

To reform road safety, it is extremely important we get good research, and the MUARC certainly does that for us. And when people stop and think about the enormous economic, physical, and emotional costs of road trauma, they realise these permeate through the entire community. Our latest campaign, for example, 'The Ripple Effect', shows how up to 200 people can be affected by one single accident, and it is not just the immediate family. We hope to get that message through to people.

Consequently, we decided to tackle road-safety reform primarily through the technology area of vehicles. We narrowed our focus to two technologies with the ability to create safer vehicles: electronic stability control (ESC) and curtain airbags. Of all the technology available, these two safety features were identified by MUARC as having the highest impact on reducing transport accidents. ESC is 
now standard technology and cuts in when vehicles wiggle to indicate drivers are going too fast. Tests have proved that such technology potentially leads to a 30 per cent reduction in single-vehicle crashes and a 40 per cent reduction in risk of death. And if we translate this to our star-rating system, there is potential for a 12 per cent increase in protection for every star attached to your vehicle. And that is a standard rating system.

So how did we go about this reform? We had a choice. We could have gone to Canberra and sought a national approach; we could have lobbied the government to change the law and mandate that people buy safer cars. But that would have taken considerable time, and probably would not have been high on their list of priorities. Alternatively, we could have gone down a regulatory path-but again, we could still be arguing over the terms of reference of any committee that was set up to tackle that issue.

To avoid these pitfalls, we turned to a more innovative approach. And I acknowledge that as a government enterprise we can be significantly nimbler, within the terms of legislation, than perhaps a department can. So I give credit to the Victorian Government for setting up the TAC to be able to facilitate these approaches.

The TAC Board took a deliberate policy decision to engage with the community and to have them demand safer cars. Essentially, the policy approach aimed to get the public leading the policy reform, rather than the other way around. We called it a market-demand model, and the goal was to encourage consumers to demand safety features, therefore pressuring the manufacturers to respond.

Our web site and media coverage were an important part of this strategy, as the more times safety features can be publicised, the more people will demand them when buying new vehicles. And the more people demand them when buying, the more likely manufacturers are to tailor their products to suit the market. The intent was for people to walk into showrooms and say 'if it doesn't have electronic stability control, I'm not interested'.

While we succeeded in eventually attaining a five-star safety system, it is important to understand, however, that at the time the strategy was not without its critics. Many argued that jobs would be put at risk if the public started to demand these features and that local production in particular would suffer. It was also called a 'pie in the sky' idea devised by road-safety boffins, even though it was actually evidence based.

This is an important point, because however simple or good a reform is, not everybody gets onboard immediately. Consequently, when we are speaking about long-term reform - and this is a 10-year journey - we must be prepared 
to stick the course and fight for change. I am extremely proud to head an organisation that was able to achieve that, and did not waiver and say after a couple of years 'oh, well, that's not being taken up, we should abandon it'.

We were fortunate to be able to use the mass media to do these things, and we also established a web site to try to infiltrate the consciousness of buyers. But we recognised it was important to use different tools. The web site was created to provide the information about the safety features on cars, and the TAC had to promote it everywhere we went, because it is not the sort of web site that would just pop up on somebody's Facebook page.

Because we know information is power, this web site has played an important role in raising the issue of safety in influencing vehicle-purchase decisions. The duel themes of education and emotion have been present throughout TAC campaigns, and have been key ways in which we have influenced people's thinking and actions. We knew we were starting to have success when we saw headlines in motor journals along the lines of 'stability control for every Camry soon'. But one or two headlines does not equal success.

As car manufacturers will tell you, the only problem with ESC is that not many people know what it is. Even describing it is difficult, but as a technology it saves lives. And if it saves lives, it is a good thing to have. By increasing the exposure of ESC, TAC was thus influencing not simply consumers, but also manufacturers. And although they were struggling to define what it was, they knew that it was a good point. In time, the safety features started moving into standard features rather than optional extras.

At that point the manufacturers themselves started using the star ratings to promote their own cars. That is when we knew we really had some grip and successes were achieved. For instance, we should recall that in 2006 less than one-fifth of Victorians had ESC in their cars. By 2008 that percentage was more than 40 per cent and today the figure stands at just more than 67 per cent. Thus, much has been achieved in just five years. The benefits will also be felt in the longer term as people sell their cars, and these vehicles start to go through the second-hand car market, meaning the whole fleet will gradually be populated with safer vehicles.

We also worked with trucking companies and other car fleets to help understand buyers' decisions. And we keep trying to get the message out there that safety is more important than anything else. We are now combining this safety message with the environmental message - pushing eco-driving - because if we push eco-driving it is going to result in safer driving. And that will have the next tranche of advocates for safety. 
Education was a vital part of our strategy, and educating the key intermediaries the salespeople in the car yard-was vital when spreading the message of car safety. We supplemented this through education in schools, and through sponsorship of the TAC Cup, Victoria's premier under-18 Australian football competition. Again, we were focusing on the consumer to challenge the salespeople. To encourage this, we urged consumers to look at the Australasian New Car Assessment Program (ANCAP) web site and the star-rating system, so they could challenge the salespeople on the subject of safety features. We thought we had a better chance of success in an informed market.

Of particular concern to us was the well-publicised over-representation of adolescents in road accidents. We needed to influence the purchasing decisions of younger or new car drivers. For the most part, young people's buying decisions are going to be influenced by two principal factors: price, and their parents. Consequently, we had to educate parents of the importance of safe vehicles for their children, and wait for the new safer cars to go through the system. The supply of safer second-hand cars was a key indicator. We knew we could not change everything overnight. First and foremost though, we wanted young people to drive safely, so they did not need the safety features. Second, we had to wait for a time when those cars would start to flow through the system, and unfortunately, that might be up to 20 years away.

To ensure young drivers got off to the best possible start, we also had the 'L120' campaign, whereby L-plate drivers must experience 120 hours in different driving conditions before getting their licence. As earlier stated, our sponsorship of the TAC Cup was also instrumental in improving the driving habits of young people.

\section{Having the desired impact}

While road safety does not have a simple, single solution, the principal lesson we have learned is that it can be improved through years of work, sticking to the message, building momentum and influencing behaviour. For the results, one need only look at the fact that Australia is a world leader in this fieldsomething of which we should be proud. Many Australian lives have been saved simply by installing ESC in cars. Further, thanks to this technology, many accidents that have occurred have resulted in people being injured rather than killed. That is the real benefit of this reform.

As a consequence, thousands of people have not had to endure the devastation of road trauma. Some of our advertisements give a small insight into the impact that road trauma can have on people's lives. And if you put yourself in those people's shoes, you cannot put a cost on the change in people's lives. It is a very sobering thought. 
And though we are pleased to have influenced consumer behaviour, we cannot become complacent. We need to also focus on the uptake of side-curtain airbags, and that will have a huge difference on the number of people who finish up with a brain injury, because of the cushioning of people's heads when they do have accidents. And once again Victoria is leading the nation in the take-up of the standard fitment of curtain airbags. In effect, in 2001 only 3 per cent of new cars sold had this feature; the figure currently stands at more than 50 per cent. This is another tremendous result, and a great example of real public-policy reform.

To avoid complacency, we also diligently track the impact of our campaigns. For example, if we are getting no traction with our campaigns then we know we must take a different approach. We are thorough in monitoring our progress, and one of the most depressing parts of my job is getting the daily road-toll bulletin delivered to my desk each morning. Such monitoring, combined with consumer sentiment, discipline, rigour and the advice of our expert board, prevents complacency at the TAC.

The TAC has deliberately tried to pursue a market-demand model, and history shows this has been a wise choice. This does not mean, however, that we do not work through government or industry players; it is a multi-pronged strategy working through road-safety partners and with successive governments. We are fortunate in this regard to have always had bipartisan support.

By giving good advice to governments and influencing the road-safety debate in a positive way, the TAC is testament to the fact that legislative change is not the only way to achieve reforms, and that government bodies can lead and influence behaviour in the marketplace. I have used road safety as an example, but the anti-smoking and the QUIT campaigns have worked similarly as educational policy instruments.

\section{Entrenching road-safety reforms}

In the case of implementing road-safety reforms, if the government had taken a solely regulatory route, we might still be arguing about the terms of reference. Instead though, due largely to the efforts of the TAC, as of December 2010, all new cars sold in Australia will be required by law to have ESC, with head protection becoming mandatory one year later.

Once again, it was Victoria that was the first jurisdiction in Australia to announce that ESC would be mandatory. For a period, there was some doubt at the national level about whether the nation would join us, but it has now come onboard. We acknowledge, however, that the TAC did not do this on its own. We worked with Victoria Police, Vic Roads and the Justice Department to ensure a complete package was created. 
But it is really the momentum in the community that has made this reform work - the awareness, the web site, the technology and the availability of the information. We have encouraged a situation where people now demand safety features; it is no longer an 'option'. One need only consider the fact that car manufacturers actively use the five-star safety-rating system as a point of competitive advantage - an outcome nobody would have predicted 20 years ago. The TAC is a good example of making policy reform stick, because vehicle safety is now embedded into policy, and saving countless lives in the process.

The aspects of the TAC I have discussed in this chapter are only part of our broader plans for improving transport safety. At the same time as we are informing the public through advertising, for example, we are funding $\$ 30$ million a year in road safety on intersection treatments and other parts of our road infrastructure. Moreover, we fund extra police campaigns, such as cracking down on people driving without seatbelts - a crime that seems unfathomable nowadays, but which is sadly still a problem. It would be wrong to assume the TAC is focused solely on improving car safety, because we are dedicating tens of millions of dollars to addressing transport accidents in other areas, with the ultimate aim of building up tangible exponential benefits over time.

In conclusion, has the campaign for road-safety reform been run and won? We still have about 300 people killed on our roads every year, and although that was a record low last year (305), it is 305 too many. As with occupational health and safety, here, the only acceptable figure is zero, and we will not rest until that is achieved. If there is one thing we have learned in the years of this campaign it is that we have to continue to innovate and push the boundaries. We cannot simply congratulate ourselves for winning the latest advertising award; we must stick to the task at hand. Because we operate from the premise that no-one should be killed on the road, our vision is a future in which every journey is a safe one. In order to achieve this, we need to continue to challenge ourselves and the community, to engage the public in debate and continue the reform process. 